\title{
Bacterial colonization and the development of intestinal defences
}

\author{
Hai Ning Shi DVM PhD, Allan Walker MD
}

\begin{abstract}
HN Shi, A Walker. Bacterial colonization and the development of intestinal defences Can J Gastroenterol 2004;18(8):493-500.
\end{abstract}

In humans, intestinal defences develop during gestation and, at full term, have the capacity to respond in an appropriate manner to infectious agents and foreign antigens. Before an active protective response can occur, however, the gut must first be exposed to colonizing bacteria. Colonization with diverse intestinal microbes is necessary for the development of important gut defenses such as the synthesis and secretion of polymeric immunoglobulin A and the generation of a balanced T helper (Th) cell response. Insights into normal immune physiological development of the gut have been made by studying the germ-free animal and intestinal defenses. These studies have provided insights into the physiology of immune responses. Two important immunological functions are the secretion of polymeric immunoglobulin A to protect the intestinal surface against harmful stimuli and inhibition of the systemic response to commensal bacteria and food proteins (eg, oral tolerance) to prevent chronic inflammation. Neither function exists in the germfree state, but rapidly develops after conventionalization (colonization) of the germ-free animal.

In the present review, the importance of bacterial colonization on the appearance of normal mucosal immune function and to the clinical consequences of inadequate colonization to the development of disease will be discussed. For example, excessive Th2 activity can lead to atopy, whereas Th1 predominance is found in conditions such as Helicobacter pylori gastritis and Crohn's disease. With the eradication of infectious diseases in developed countries in the past three decades, the incidence of atopic and autoimmune diseases has increased. This epidemiological observation has been explained by the 'hygiene hypothesis', which suggests that a reduction in microbial burden by public health measures has contributed to an immunological imbalance in the intestine. A family of pattern recognition receptors (Toll-like receptors) on gut lymphoid and epithelial cells mediates innate immune responses to bacterial molecular patterns and, thereby, orchestrates acquired immunity. As the role of bacterial communication within the gut (bacterialepithelial cross-talk) is clarified, physicians should be able to modulate gut immune responses, for example, by the use of probiotics.

Key Words: Bacterial-epithelial 'cross-talk'; Inflammatory bowel disease; Innate immunity; Intestinal allergy; Necrotizing enterocolitis; Toll-like receptors

\section{Colonisation bactérienne et développement des mécanismes de défense dans l'intestin}

Chez l'humain, les mécanismes de défense dans l'intestin se forment durant la gestation et, à terme, ils ont la capacité de réagir de façon appropriée aux agents infectieux et aux antigènes étrangers. Toutefois, avant que ne se produise une réaction active de protection, l'intestin doit d'abord avoir été exposé à des bactéries colonisatrices. La colonisation de l'intestin par diverses bactéries est nécessaire au développement d'importants mécanismes de défense comme la synthèse et la sécrétion d'immunoglobulines A polymériques et la production d'une réaction équilibrée des lymphocytes T auxiliaires (cellules Th). Des études sur animal axénique et sur les mécanismes de défense dans l'intestin ont permis de mieux comprendre le développement physiologique du système immunitaire et ses réactions. Celui-ci remplit deux fonctions importantes, soit la sécrétion d'immunoglobulines A polymériques pour protéger la muqueuse de l'intestin contre des agents dangereux et l'inhibition d'une réaction généralisée aux germes commensaux et aux protéines d'origine alimentaire (p. ex. tolérance buccale) pour prévenir l'inflammation chronique. Aucune de ces fonctions n'existe chez l'animal axénique, mais elles apparaissent rapidement après sa colonisation.

Il sera question dans le présent article de l'importance de la colonisation bactérienne pour le développement immunitaire normal des muqueuses et des conséquences cliniques d'une colonisation inadéquate dans l'apparition des maladies. Par exemple, une activité exagérée des cellules Th2 peut donner lieu à des manifestations atopiques, tandis qu'une prédominance des cellules Th1 est associée à des affections comme la gastrite à Helicobacter pylori et à la maladie de Crohn. Parallèlement à l'éradication des maladies infectieuses depuis une trentaine d'années dans les pays développés, la prévalence des réactions atopiques et des maladies autoimmunes a augmenté. La tendance s'expliquerait par une amélioration des conditions d'hygiène, hypothèse selon laquelle la diminution de la charge microbienne par des mesures de santé publique entraînerait paradoxalement un déséquilibre immunitaire dans l'intestin. Un groupe particulier de cellules épithéliales et de récepteurs de reconnaissance, les « toll-like receptors ", se trouvant dans le tissu lymphoïde de l'intestin déclenche des réactions immunitaires naturelles à certaines structures moléculaires bactériennes, créant ainsi une immunité acquise. À mesure qu'on comprend davantage le rôle des bactéries dans l'intestin (échanges épithéliumbactéries), les médecins devraient être en mesure de modifier les réactions immunitaires de l'intestin en utilisant, par exemple, des probiotiques.

Presented by Dr Allan Walker as the Richard D McKenna Memorial Lecture at the Canadian Digestive Disease Week in Banff, Alberta, February 2004

Mucosal Immunology Laboratory, Combined Program in Pediatric Gastroenterology, Massachusetts General Hospital and Harvard Medical School, Charlestown, Massachusetts

Correspondence and reprints: Dr Allan Walker, Mucosal Immunology Laboratory, Massachusetts General Hospital-East, 114 16th Street,

Charlestown, Massachusetts 02129, USA. Telephone 617-726-4166, fax 617-724-1731, e-mail wwalker@partners.org

Received for publication May 10, 2004. Accepted June 8, 2004 


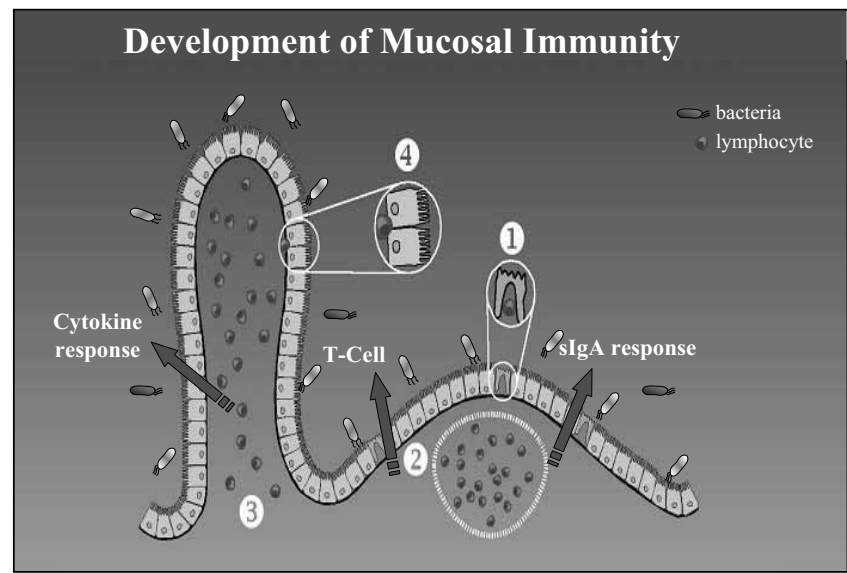

Figure 1) A diagrammatic representation of the ontogeny of the human mucosal immune system, showing the major components of the mucosal immune system. The respective developmental time points for key components are highlighted. Initially, follicular epithelial cells (M cells) (1) are apparent. Note organized lymphoid tissue, such as Peyer's patches (2), and more diffusely scattered lymphocytes in the intestinal lamina propria (3) and intraepithelial lymphocytes (4) appear. This immune system is developmentally regulated. The development and function of the mucosal immune system can be affected by colonizing intestinal bacteria. sIgA Secretory immunoglobulin A

$T^{\mathrm{h}}$ he intestinal mucosa is the interface between the external and internal environments, and separates gut luminal antigens, such as bacteria, bacterial products and food, from the largest population of lymphocytes in the body. At birth, the newborn infant leaves the germ-free intrauterine environment to enter a highly contaminated extrauterine world, which requires strong host defences to prevent the acquisition of gastrointestinal and systemic diseases. Intestinal defenses develop during gestation, and at full term, have the capacity to respond in an appropriate manner to infectious agents and foreign antigens (1). However, before an active protective response can occur, the gut must first be exposed to colonizing bacteria. Colonization of the intestine with micro-organisms plays an important role in stimulating the normal development of the immune system, including the gut-associated lymphoid tissues (GALT), and important gut defences such as the synthesis and secretion of polymeric immunoglobulin $\mathrm{A}(\operatorname{IgA})$ and the generation of a balanced $\mathrm{T}$ helper ( $\mathrm{Th}$ ) cell response. Colonization begins as the newborn enters the birth canal, with exposure to maternal vaginal and colonic flora (2). Additional stimulation occurs with the introduction of enteric feeding (either breast milk or formula) and at weaning (3). Complete colonization with a large variety of organisms (more than 400 different species reside in the colon) occurs by two years of age. The number of microbes that ultimately colonize the gut exceeds the total number of cells in the body. Insights into normal immune physiological development of the gut have been made by studying the germ-free animal and intestinal defences. Animals housed in a germ-free environment show impaired development of the immune system and weak immune responses. The colonization of germ-free animals with intestinal commensal flora fosters the development of the immune system.

It is clear that there is a complex relationship between the intestinal immune system and commensal flora. Because mucosal surfaces are colonized by a large, complex and dynamic collection of bacteria, it is extremely important for intestinal epithelial cells and the mucosal immune system to distinguish between pathogenic and nonpathogenic bacteria and to generate an appropriate response while maintaining a state of homeostasis with normal microbial flora. The cellular interactions between intestinal epithelial and immune cells are thought to be important for the initiation and regulation of the immune response to luminal bacterial antigens. Colonization of intestinal mucosal surfaces with normal intestinal flora is purported to be necessary for the development of tolerance to dietary antigens (4), whereas certain intestinal bacteria (probiotics) may be able to preferentially stimulate subsets of Th cells (Th1 and Th2) and, thereby, modify intestinal inflammatory and allergic responses (5). The present review discusses the role of intestinal bacterial colonization in regulating the development and function of the intestinal mucosal immune system and in the pathogenesis of intestinal diseases.

\section{GALT}

GALT are the largest collection of lymphoid tissues in the body. They consist of organized lymphoid tissues, such as mesenteric lymph nodes and Peyer's patches (PP), and more diffusely scattered lymphocytes in the intestinal lamina propria (LP) and epithelium (Figure 1), including large numbers of $\operatorname{Ig} \mathrm{A}^{+}$plasmablasts.

Polymeric IgA, one of the key components of the intestinal humoral immune system, defends mucosal surfaces against environmental microbes. Germ-free mice have fewer than normal IgA-secreting plasmacytes (6). Monocolonization with segmented Gram-positive filamentous bacteria, a major constituent of the commensal flora, induced a robust mucosal IgA response in both PP and LP (7). It has been suggested that specific intestinal mucosal IgA can be induced by commensal bacterial antigens through a pathway that is independent of $\mathrm{T}$ cells and of the influence of follicularly organized lymphoid tissue (8).

It is well established that colonization with bacteria is critical to the normal structure and optimal function of the mucosal immune system (9). Early studies established that germ-free mice exhibit smaller PP (6) and fewer intraepithelial lymphocytes (10) than specific pathogen-free or germfree mice colonized by single or multiple species of bacteria. A recent study (11) using gnotobiotic rats showed that, under germ-free conditions, the follicle-associated epithelium (FAE) contained only a few $\mathrm{T}$ and $\mathrm{B}$ cells, and that the $\mathrm{B}$ cells were negative for CD86, a co-stimulatory molecule necessary for $\mathrm{T}$ cell activation. After bacterial colonization, however, the number of $\mathrm{T}$ cells and $\mathrm{CD}^{+} 6^{+} \mathrm{B}$ cells in the FAE increased dramatically (11). Furthermore, this study showed that, before microbial colonization, immature $\left(\mathrm{CD}^{-} 0^{-}\right.$or $\left.\mathrm{CD}^{-} 6^{-}\right) \mathrm{CD}^{+}$dendritic cell (DC) subsets were detected in the FAE. This subset disappeared from the FAE soon after colonization, probably as a result of rapid DC migration to the interfollicular $\mathrm{T}$ cell zone, where $\mathrm{DC}$ activation/maturation and stimulation of naive $T$ cells are known to take place (Figure 2 ). The results of this study suggest the involvement of microbial colonization in organizing the spatial relationships between B cells, T cells and DCs in PP (11). Intestinal antigen-transporting $M$ cells are also affected by luminal bacteria. Colonization of germ-free mice with Salmonella typhymurium aroA resulted in a two- to threefold increase in the number of $\mathrm{M}$ cells (12). 
One of the key functions of GALT is to distinguish innocuous antigens from pathogenic micro-organisms and to elicit an appropriate response. Intestinal microflora can significantly affect these responses. Intestinal bacterial antigens are believed to play a role in the activation of $\mathrm{T}$ cells because the majority of $\mathrm{T}$ lymphocytes from intestinal lymphoid tissues show an activated or memory phenotype. Monocolonization of germ-free animals can result in the activation of mucosal $\mathrm{T}$ cells that are otherwise quiescent. Unrestrained mucosal immune activation in response to bacterial signals from the lumen, however, is a risk factor for autoimmune disorders such as inflammatory bowel disease (IBD).

The development and function of GALT are precisely regulated by mechanisms that are still not fully understood. Regulatory $\mathrm{T}$ (Treg) cells may play a role in the modulation of mucosal immune responses. In the absence of Treg cells, gut bacteria trigger the development of severe IBD. An animal study (13) demonstrated that the transfer of $\mathrm{CD}^{+}{ }^{+} \mathrm{T}$ cells to mice lacking the $\mathrm{CD} 25^{+}$subset led to colitis if the hosts were colonized by enteric bacteria. Adoptive transfer of Treg cells into these mice, however, prevented the expression of disease.

Immune responses to food proteins (allergy) or self-antigens (autoimmunity) may also result from failure to precisely regulate the mucosal immune system. Although intestinal $\mathrm{T}$ cells express an activated phenotype and are richly populated by memory cells, they proliferate poorly in response to in vitro $\mathrm{T}$ cell stimulation. Human mucosal $\mathrm{CD}^{+}{ }^{+} \mathrm{T}$ cells have been shown to suppress the proliferation of peripheral blood $\mathrm{T}$ cells in response to antigen pre-pulsed antigen presenting cells (APC) in a co-culture system (14). This inhibition was independent of cell contact and was reversed by the neutralization of interleukin (IL)-10 or transforming growth factor-beta (TGF- $\beta$ ) with monoclonal antibody, suggesting that specific antigen recognition might play a role in maintaining mucosal $\mathrm{T}$ cell unresponsiveness to intestinal bacterial antigens. Germfree animals have been shown to be partially or totally resistant to the induction of oral tolerance to some antigens $(4,15-17)$. The priming of helper T cells in GALT by bacterial antigens might also help enable these cells to rapidly respond to the cognate antigen in peripheral lymphoid organs (18).

GALT can be divided into discrete inductive and effector sites, consisting of PP, LP and mesenteric lymph nodes, containing both $\mathrm{CD}^{+}$and $\mathrm{CD}^{+} \mathrm{T}$ cells. A subpopulation of $\mathrm{CD}^{+}$ $\mathrm{T}$ cells that co-express CD25 (the alpha-chain of IL-2 receptor) exhibits a regulatory function in the mucosa and may be generated by exposure to luminal antigens. These cells appear to play an important role in the induction and maintenance of tolerance in normal intestine through the production of TGF- $\beta$ and IL-10, and the ligation of cytotoxic T lymphocyte antigen 4 (19).

Treg cells, such as $\mathrm{CD} 4{ }^{+} \mathrm{CD} 45 \mathrm{RB}^{\text {lo }}$ and $\mathrm{CD} 4{ }^{+} \mathrm{CD} 25^{+}$, are potent immune suppressors that control or prevent the development of spontaneous autoimmune disease (20). They also prevent the excessive immune response to intestinal microflora that leads to IBD (21). A recent study (22) examined the role of microbial products in activating these regulatory cells and showed that Treg cells respond directly to proinflammatory bacterial products, including lipopolysaccharide (LPS). LPS treatment enhanced the suppressive function of these cells by interacting with the Toll-like receptor (TLR)-4 receptor molecule (22). In addition, this study also demonstrated that a subset of CD4 cells

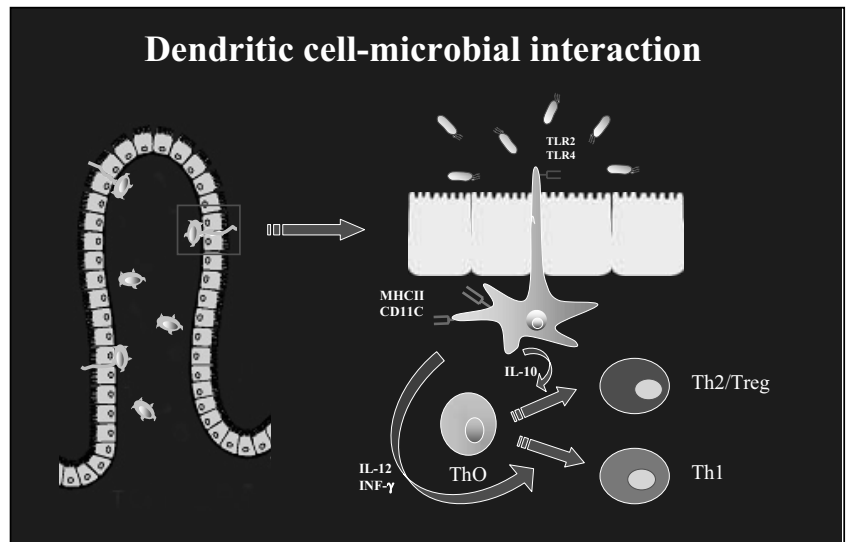

Figure 2) A diagrammatic represention of dendritic cell-microbial interaction. Dendritic cells in the lamina propria of the gut can sample luminal flora by extending appendages across tight junctions into the lumen. By interacting with pathogen-associated molecular patterns on Gram-positive and-negative bacteria via pattern recognition receptors (eg, Toll-like receptors [TLRs]), immature dendritic cells can mature to express surface molecules and release cytokines which favour naïve $T$ helper $(T h)$ cells maturing into various subclasses of Th cells (eg, Th1, Th2 and Th3). IL-10 Interleukin-10; INF- $\gamma$ Interferon gamma; MHCII Major histocompatibility complex II; Treg Regulatory T cells

$\left(\mathrm{CD} 45 \mathrm{RB}^{\text {lo }} \mathrm{CD} 25^{+}\right)$selectively express TLR4, TLR5, TLR7 and TLR8 (22), providing a link between the innate and adaptive immune responses.

\section{BACTERIAL EPITHELIAL CROSS-TALK AND BACTERIAL ANTIGEN UPTAKE}

Colonization of the gastrointestinal tract by normal bacterial flora is often cited as a basic defence mechanism of the body against infection by pathogens $(23,24)$. Gnotobiotic mice or rats are much more susceptible than their conventionally reared counterparts to infection with Salmonella enteritidis, Listeria monocytogenes, Clostridium difficile and Helicobacter pylori. That neonatal animals and infants are more susceptible than adults to infections may be related to the change in the composition and density of gut flora after weaning. Alternatively, weaning may alter the gut flora, which may strengthen the mucosal immune system $(23,25)$.

Colonization of the intestinal lumen begins at birth. The maternal microflora can be a source of bacteria for the newborn's intestine. Colonization can also be affected by environmental factors and infant feeding patterns. Breastfeeding encourages the growth of bifidobacteria, whereas formula-fed infants have a more complex flora made up of bifidobacteria, bacteroides, clostridia and streptococci. Bacteria may use microvillus membrane glycoconjugates as target cell receptors for adhering to the epithelium. The activities of glycosyltransferases, the enzymes responsible for synthesizing brush border glycoconjugates, are under tissue-specific and developmental regulation in mice (26). The intestinal flora has been shown to regulate specific glycosyltransferases (Figure 3) (26).

Even though intestinal epithelial cells are normally covered by a wide variety of microbes (up to 500 species of bacteria), they form a mechanical barrier that separates the external environment from the host's internal milieu. Intestinal epithelial cells are also capable of detecting bacterial antigens (or products) and initiating, participating in and regulating both innate 


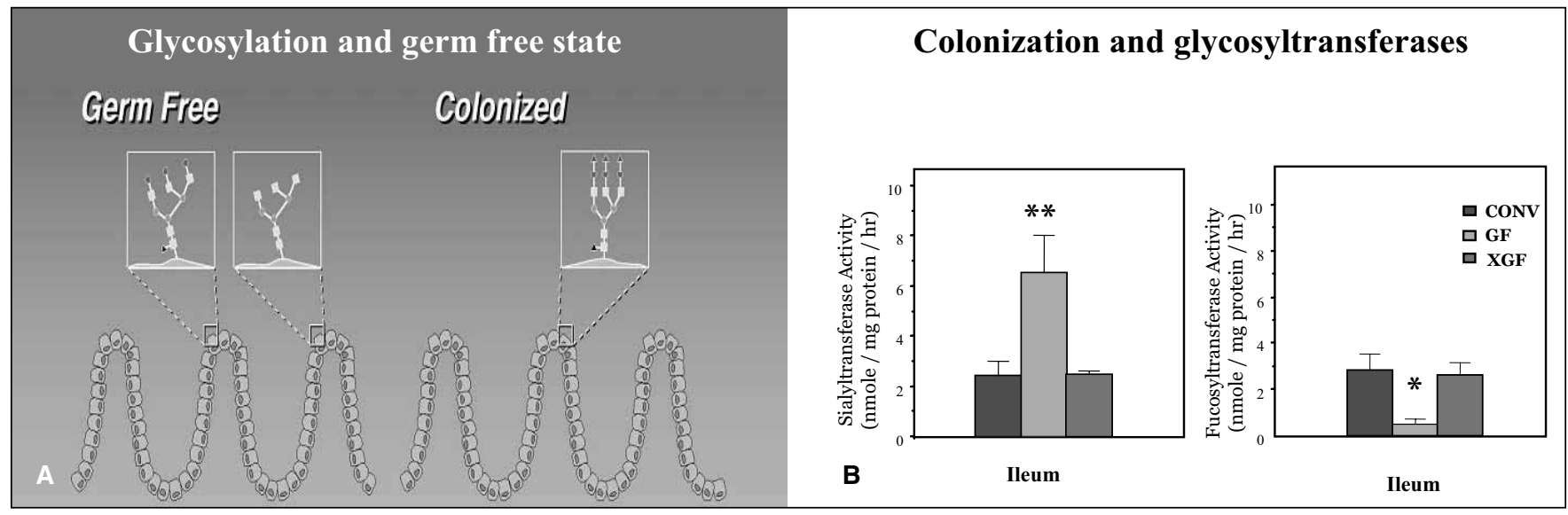

Figure 3) Cell surface glycoconjugates serve as adhesion sites for a variety of microbes. Glycosylation is a developmentally regulated process. Luminal bacteria are important extrinsic regulators of fucosyltransferases in the gut. In germ-free mice, the level of these glycosyltransferases maintain an immature pattern of surface glycosylation (A), whereas bacterial colonization initiates the developmental induction of fucosyltransferase (B). CONV Conventional; GF Germ-free; XGF Ex-germ-free

\section{TABLE 1}

Toll-like receptors (TLRs) and their ligands

\begin{tabular}{ll}
\hline TLRs & Ligands \\
\hline TLR1 & $\begin{array}{l}\text { Triacyl lipopeptides } \\
\text { Lipoprotein/lipopeptides, peptidoglycan, } \\
\text { TLR2 }\end{array}$ \\
TLR3 & $\begin{array}{l}\text { Doubleichoic acid, etc } \\
\text { TLR4 }\end{array}$ \\
TLR5 & Flagellin \\
TLR6 & Diacyl lipopeptides \\
TLR7 & Synthetic compounds (the immune response modifiers) \\
TLR8 & Unknown \\
TLR9 & CpG-DNA \\
TLR10 & Unknown \\
\hline
\end{tabular}

HSP Heat shock protein; LPS Lipopolysaccharide

and adaptive immune responses. They do this by transducing signals from luminal pathogens to adjacent immune cells in the LP, such as the macrophages, DCs and lymphocytes that form the intestinal mucosal immune system, via molecules expressed on the epithelial cell surface such as major histocompatibility complex I and II molecules, and TLRs (27-30). TLRs on epithelial cells may enable the epithelium to discriminate between normal commensal flora and pathogens, and induce the activation of a panel of genes mediating immune and inflammatory responses. Therefore, TLRs play an important role in signalling innate immune pathways, and in initiating and regulating adaptive immune responses. An imbalance or point mutation on these receptors can represent risk factors in conditions such as Crohn's disease (31).

TLRs are a family of transmembrane receptors homologous to Drosophila Toll proteins (32-34). Recognition of bacterial molecular patterns by the innate immune system is dependent on the interaction between TLRs and pathogen-associated molecular patterns (PAMPs) present on diverse microbes. To date, 10 members of the TLR family have been identified in mammals, with each receptor recognizing a unique set of PAMPs (Table 1). TLR2 is responsible for recognizing bacterial lipoproteins and peptidoglycan (PGN); TLR3 recognizes double-stranded RNA; TLR4 is essential for responses to LPS;
TLR 5 controls responses to bacterial flagellin; TLR7 responds to the immune response modifiers (imidazoquinolines); and TLR9 is required for the recognition of unmethylated $\mathrm{CpG}$ DNA motifs characteristic of bacterial DNA. Recent studies (35) have suggested that TLRs may control the induction of adaptive Th1 responses. There is also evidence that TLRs may be important for Th2-type responses by augmenting the overall maturity of DCs (35).

The intestinal epithelium, which is continually exposed to a large variety of commensal bacteria and PAMPs, has been shown to constitutively express several members of the TLR family in vitro and in vivo $(26-28,36,37)$. It is well established that the interaction of TLR with its PAMP results in the activation of intracellular signalling pathways, nuclear translocation of transcription factors, such as nuclear factor kappa B, and the transcription of cytokines, such as IL-8 (Figure 4).

Cario and Podolsky (28) characterized the expression pattern of TLR2, TLR3, TLR4 and TLR5 in intestinal mucosa of patients suffering from IBD and normal controls. Using immunohistochemistry, they observed a differential expression of TLRs in intestinal epithelial cells, in that there was constitutive expression of TLR2 and TLR5, and a low-level expression of TLR4 in normal cells. In contrast, intestinal epithelial cells from patients with IBD exhibited an upregulated expression of TLR4, downregulated expression of TLR3, and unchanged TLR2 and TLR5 expression (28). A study by Fusunyan et al (29) on a nonmalignant human fetal primary small intestinal cell line (H4 cells) and in human fetal small intestinal enterocytes showed that TLR2 and TLR4 were expressed constitutively, and that the transcription of TLR2 and TLR4 was regulated by inflammatory stimuli. The authors observed that IL-1 $\beta$ stimulation resulted in an increased expression of both TLR2 and TLR4, whereas LPS decreased TLR4 expression in both $\mathrm{H} 4$ cells and human fetal small intestinal enterocytes. A study by the Sanderson group (38) showed that TLR4 messenger RNA (mRNA) was expressed in peripheral blood mononuclear cells, but was not present in epithelium from children with IBD.

The expression of TLRs in intestinal epithelial cells has also been studied in an animal model. Ortega-Cava et al (39) examined the localization of TLR4 compared with that of TLR2 and CD14 along the luminal gastrointestinal surface of 


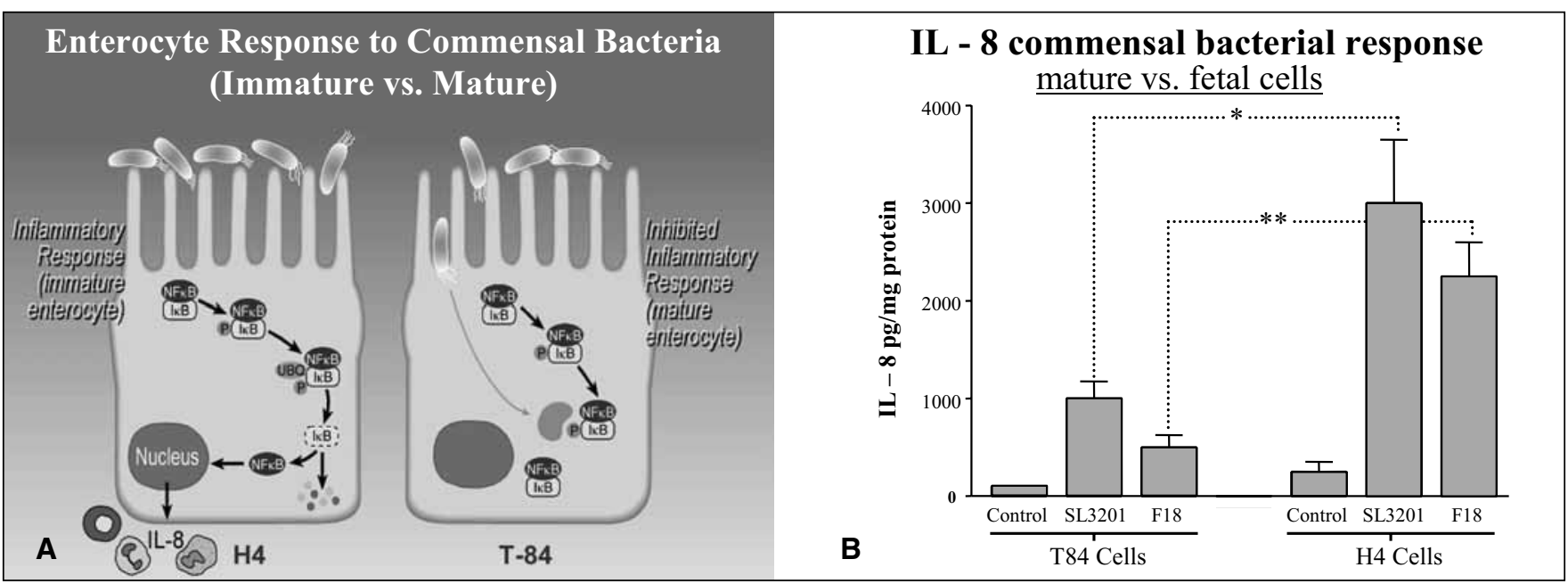

Figure 4) Enterocyte response to commensal bacteria in immature and mature cell lines (A). Because of the underexpression of signalling molecules (eg, inhibitory kappaB $[I \kappa B])$ in immature cells, inflammatory cytokines are produced, in contrast to mature cells where anti-inflammatory responses predominate. Panel B demonstrates the interleukin-8 (IL-8) response in mature intestinal human cell lines (T-84) versus an immature human cell line (H4) to a pathological (SL3201) salmonella strain expressing flagella and to a commensal Escherichia coli (F18) strain expressing flagella. Immature enterocytes have an enhanced response to both pathological and commensal bacteria, in contrast to mature enterocyte response. H4 cells secreted a higher amount of IL-8 than T-84 cells in response to *salmonella and **E coli. NFאB Nuclear factor kappa B; P Phosphate; UBQ Ubiquitin

normal mice and mice with dextran sodium sulfate-induced IBD. They found that TLRs were differentially expressed along the mouse gastrointestinal tract, with higher levels of TLR4 and CD14 mRNA and protein detected in the distal colon, and stronger TLR2 mRNA expression in the proximal colon. The authors also observed that all genes studied (TLR2, TLR4 and CD14 MyD88) were upregulated during dextran sodium sulfate-induced inflammation, which is localized to the distal colon (39).

To understand how the normal intestinal epithelium deals with continuous exposure to commensal Gram-positive bacteria (which possess PAMPs, including PGN and bacterial lipopeptides that are recognized by TLR2), Melmed et al (37) isolated human colonic epithelial cells by laser capture microscopy and used intestinal epithelial cell (IEC) lines (Caco-2, T84 and HT-29), and reverse transcriptase polymerase chain reaction (PCR) and quantitative realtime PCR to analyze the expression of TLR2, TLR6, TLR1 and Toll inhibitory protein mRNA. They found that colonic epithelial cells and LP lymphoid cells from both healthy and inflamed tissue expressed low levels of TLR2 and high levels of the Toll inhibitory protein, and that IECs were unresponsive to TLR2 ligands. The observation that IECs expressed a low level of TLR2 was consistent with previous observations by Cario et al (27) and by the Sanderson group (38) that TLR2 mRNA was highly expressed in peripheral blood mononuclear cells and was present in all human IECs. These results indicate that TLRs expressed on intestinal epithelium are regulated by bacterial flora and host mucosal immune responses. TLRs on IECs may play a role in the induction of an inflammatory response to bacterial pathogens and in the development of tolerance to nonpathogenic commensal organisms.

Intestinal bacteria, especially pathogenic ones, are believed to be taken up and actively translocated by specialized epithelial cells, $\mathrm{M}$ cells, which are derived from villous epithelial cells located over PP. A study by Rescigno et al (40) found that DCs, which are crucial to the recognition of bacterial antigens and in the defence against pathogens, expressed tight junction protein and could open the tight junctions between epithelial cells and, thus, take up bacteria directly without compromising epithelial barrier function. As an initiator of adaptive immune responses, mucosal DCs either infiltrate the intestinal LP diffusely or form subepithelial aggregates scattered along the small and large intestine (41).

DCs are activated via TLRs expressed on their surface. Liu et al (42) observed that myeloid and lymphoid subsets of DCs express different TLRs. Specifically, human myeloid preDC1s, but not lymphoid pre-DC2s, express TLR2 and TLR4, whereas lymphoid pre-DC2s, but not myeloid pre-DC1s, express high levels of TLR7 and TLR9. The activation of TLRs induces DC expression of various cytokines, such as tumour necrosis factor-alpha (TNF- $\alpha$ ), IL-6 and IL-12. IL-12 can induce Th cells to differentiate into Th1 effector cells (42). Recent evidence has revealed differences in TLR expression on murine DC subsets. Reverse transcriptase-PCR has been employed to detect the mRNA of most TLRs, including TLR1, TLR2, TLR4, TLR6, TLR8 and TLR9, on all DCs. A difference in TLR3, TLR5 and TLR7 expression was found between $\mathrm{CD} 8 \alpha^{+}$and $\mathrm{CD} 8 \alpha^{-} \mathrm{DC}$ subsets (43). There are also strain-specific differences: TLR2, TLR4, TLR5 and TLR6 are strongly expressed on DCs from BALB/c mice, but TLR9 is preferentially expressed in C57BL/6 mice (44). The functional significance of these differential expressions of TLRs on DCs and DC subsets remains to be further elucidated.

TLRs expressed on DCs constitute a critical link between antigen recognition and the induction of $\mathrm{T}$ cell immunity. Triggering of TLRs by various microbial stimuli may drive DCs to assume distinct phenotypes and functions. Using LPS (TLR4 ligand) and PGN (TLR2 ligand), Re and Strominger (45) showed that human DCs preferentially express IL-12 and IL-10 when stimulated through TLR4 and TLR2, respectively. Similar observations were made in an animal study (46) that demonstrated that LPS-stimulated DCs produced high levels of IL-12 and low levels of IL-10, whereas DCs exposed to PGN 
produced low levels of IL-12 and high levels of IL-10. On the other hand, Higgins et al (47) recently showed that signalling through TLR4 in response to Bordetella pertussis activates IL-10 production from DCs, suggesting that the TLR4 pathway may promote the development of IL-10-secreting Treg cells, thereby suppressing the inflammatory response. It is clear that patternrecognition receptors on IECs and APCs play an important role in mediating the continuing dialogue between the host and gut microbiota, and in generating the appropriate response.

\section{BACTERIAL COLONIZATION AND DISEASE}

Because the gut mucosa is in continuous, direct contact with the intestinal flora, the GALT must develop mechanisms to distinguish between pathogens and commensal flora, and determine whether tolerance or an immune response should be induced. A breakdown of the tightly regulated mucosal immune response may result in inappropriate reactivity of the intestinal mucosa against luminal antigens. In fact, a triggering role of intestinal bacteria in chronic intestinal inflammation has been suggested by both clinical observations and animal experiments. A large concentration of mucosal bacteria was detected in patients with IBD but not in healthy controls (48), suggesting that a healthy mucosa may prevent close contact of the luminal flora with the epithelial surface. It is known that murine lymphocytes do not proliferate when stimulated with bacterial antigens from their own intestinal flora, indicating the development of immunological tolerance.

Increased mucosal permeability, often occurring with IBD, allows the entry of bacterial antigens. The interaction of certain commensal bacteria with the mucosa triggers mucosal inflammation. The gut flora is, therefore, the key factor driving the inflammatory process that leads to intestinal lesions. Both the innate immune system and Treg cells likely regulate the mucosal immune system.

Abnormalities of the intestinal microflora early in life may also lead to immune disturbances. Intestinal microorganisms induce a Th1 response that may balance Th cell responses in the mucosa. Delayed or aberrant colonization early in life may result in a reduced capacity of APCs to provide pro-Th1 signals, such as IL-12, to T cells, leading to the development of an unbalanced Th2 response and allergic reactions. A recent study by Eggesbo et al (49) considered factors that possibly delay or alter initial bacterial colonization, and discovered a sevenfold greater incidence of food allergy among children delivered by cesarean section. It was noted that the risk was especially high among those with a familial predisposition.

Bacterial colonization at birth can be affected by many factors, including the composition of the maternal vaginal microflora. Benn et al (50) recently found that maternal colonization with Ureaplasma urealyticum during pregnancy was a risk factor for subsequent infant wheezing, and that maternal colonization with staphylococci and the use of antibiotics during pregnancy were associated with asthma during the first five years of life.

Epidemiological studies in countries with different prevalences of atopic diseases (Sweden and Estonia) have suggested an association between normal gut flora and the development of allergies $(50,51)$. Children with allergies are less often colonized with lactobacilli and have higher counts of aerobic bacteria than nonallergic children. Early colonization with bifidobacteria, and low counts of bacteroides and $\mathrm{C}$ difficile also appear to be protective against allergy (52). These observations support the 'hygiene hypothesis', which suggests that inadequate exposure to bacteria favours the development of allergic disease (53).

\section{PROBIOTICS AND GUT DEFENCES}

As already discussed, colonization of the intestine, especially by certain bacteria, may contribute to the induction and maintenance of immune tolerance to luminal antigens and help prevent autoimmune disease and food allergies. There is recent evidence that commensal bacteria affect intestinal development and function (52). Probiotics are live microorganisms that are ingested to enhance health by altering indigenous microflora.

The beneficial effects of probiotics may be related to a variety of mechanisms: the regulation of cytokine production, increased release of IgA secretion, production of antibacterial substances, augmentation of tight junctions to prevent intercellular bacterial invasion and competition with pathogenic micro-organisms for adherence to enterocytes. A recent study (54) found that one probiotic species, Lactobacillus rhamnosus GG, promoted the survival of intestinal epithelial cells through the activation of antiapoptotic Akt/protein kinase B and inhibition of proapoptotic p38 mitogen-actived protein kinase pathways. The results of this study provide new insights into the understanding of the signal transduction pathways in enterocytes that are regulated by probiotics and intestinal commensal bacteria.

Lactobacilli derived from the endogenous flora of normal donors have been used as probiotics in medical foods and as vaccine stimuli. Probiotic treatment has been used to prevent some infectious and allergic diseases, and may be effective for IBD. Growing evidence from human studies and animal models of IBD implicate an aberrant response to altered enteric flora $(48,55)$. There is also evidence from a murine IL-10 knockout model that demonstrated microflora disturbances may promote intestinal inflammation (55). IL-10-deficient mice exhibited increased adherence and translocation of aerobic bacteria, even before the development of overt colonic injury. Decreased adherence of Lactobacillus species occurred during the time when histological injury was developing. Repopulation of the intestinal lumen Lactobacillus species attenuated the disease.

In a recent double-blind, placebo-controlled trial, McCarthy et al (56) found that both Lactobacillus salivairus and Bifidobacterium infantis significantly attenuated colitis in IL-10-deficient mice. The investigators found that PP lymphocytes from $B$ infantis-treated mice produced significantly less interferon-gamma and TNF- $\alpha$. There was also a significant reduction in proinflammatory cytokine production by spleen cells in the probiotic groups. However, the production of the immunoregulatory cytokine TGF- $\beta$ remained unchanged, suggesting that the probiotic effect might be mediated by altering the balance between proinflammatory and regulatory cytokines (56). It is possible that specific luminal micro-organisms could induce the production of IL-10 and TGF- $\beta$, which play important regulatory roles in the development of inflammatory and allergic responses, and in the induction of oral tolerance.

Borruel et al (57) collected samples of intestinal mucosa from 10 patients with Crohn's disease and five disease controls undergoing right hemicolectomy, and cultured the mucosa with 
nonpathogenic Escherichia coli, Lactobacillus casei, Lactobacillus bulgaricus or Lactobacillus crispatusin. They found that the production of the proinflammatory cytokine TNF- $\alpha$ by inflamed Crohn's disease mucosa was significantly reduced by co-culture with $L$ casei or $L$ bulgaricus, suggesting that probiotics may interact with immunocompetent cells at the mucosal interface and modulate the local production of proinflammatory cytokines.

Previously, in a double-blind, randomized, placebo-controlled trial, Kalliomäki et al (58) gave Lactobacillus GG prenatally to mothers, who had at least one first-degree relative (or partner) with allergy (atopic eczema, allergic rhinitis or asthma), and postnatally to their infants (Figure 5). They found that probiotic treatment significantly reduced the incidence of atopic eczema. At follow-up at four years of age, a diagnosis of atopic eczema (based on a questionnaire and clinical examination) was established in 14 of 53 children receiving Lactobacillus GG compared with 25 of 54 children receiving placebo (59). This observation suggests that the preventive effect of Lactobacillus GG on atopic eczema extends beyond infancy.

Lodinova-Zadnikova et al (60) reported that colonization of the intestine with a probiotic form of $E$ coli after birth resulted in a significant decrease in the incidence of allergies and repeated infections both 10 and 20 years later. Intestinal flora may also promote potentially antiallergenic processes by inducing Th1-type immunity. The gut microflora can play a suppressive role in the development of a Th2-skewed immune response in fetuses and neonates.

\section{SUMMARY}

Bacterial colonization plays an important role in the normal development, differentiation, function and regulation of the intestinal mucosal immune system. Through mechanisms that are still not fully understood, the intestinal mucosal immune system generates protective immunity against pathogen invasion and, at the same time, induces immune tolerance, preventing the development of autoimmunity (IBD) and food allergy. The regulatory role of the intestinal flora in the development and function of the intestinal mucosal immune system is well established. Recent work has suggested that colonization with probiotics in the gut may play an essential role in balancing the functions of Th1, Th2 and Th3 cell populations. This action may contribute to the induction and maintenance of immunological tolerance to

\section{REFERENCES}

1. Insoft RM, Sanderson IR, Walker WA. Development of immune function within the human intestine and its role in neonatal diseases. Pediatr Clin North Am 1996;43:551-71.

2. Kohler H, McCormick BA, Walker A. Bacterial-enterocyte crosstalk: Cellular mechanisms in health and disease. J Pediatr Gastroenterol Nutr 2003;36:175-85.

3. Yoshioka H, Iseki, K, Fujita K. Development and differences of intestinal flora in the neonatal period in breast-fed and bottle-fed infants. Pediatrics 1983;72:317-21.

4. Moreau MC, Corthier G. Effect of the gastrointestinal microflora on induction and maintenance of oral tolerance to ovalbumin in $\mathrm{C} 3 \mathrm{H} / \mathrm{He}$ mice. Infect Immun 1988;56:2766-8.

5. Sutas Y, Hurme M, Isolauri E. Down-regulation of anti-CD3 antibodyinduced IL-4 production by bovine caseins hydrolysed with Lactobacillus GG-derived enzymes. Scand J Immunol 1996;43:687-9.

6. Moreau MC, Ducluzeau R, Guy-Grand D, Muller MC. Increase in the population of duodenal immunoglobulin A plasmocytes in axenic mice associated with different living or dead bacterial strains of intestinal origin. Infect Immun 1987;21:532-9.

\section{Probiotics and allergy prevention (2yrs)}

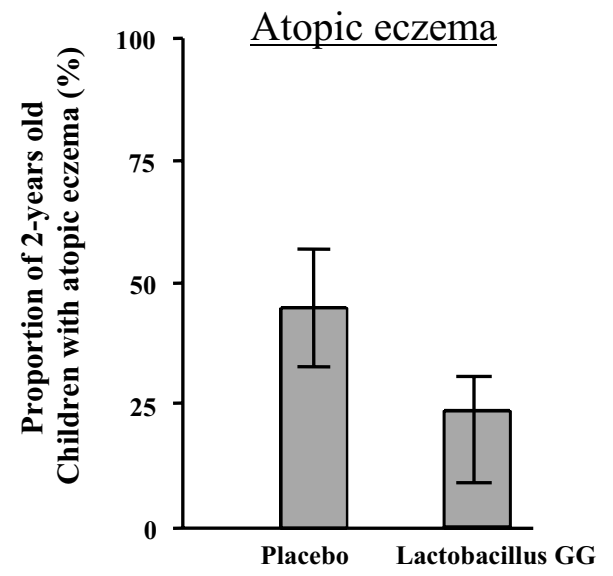

Figure 5) Atopic response in allergy prone infants treated in utero and during the first six months of life with Lactobacillus GG versus placebo. The infants treated with probiotics had 50\% less atopic dermatitis at two years of age than did infants treated with the placebo (Reproduced with permission from Kallimaki et al (58). yrs Years

other luminal antigens in the normal host or to the inhibition of dysregulated responses induced by luminal antigens in diseased hosts. A better understanding of the cellular and molecular mechanisms controlling the development and regulation of the intestinal mucosal epithelial system by intestinal bacteria (commensal and probiotics), and their regulatory role in various diseases will help establish new strategies to prevent and control these conditions.

ACKNOWLEDGEMENTS: The authors acknowledge the research funding from the Charles $\mathrm{H}$ Hood Foundation, Boston, Massachusetts; and National Institutes of Health (KO1 Award, DK59996) and First Award from the Crohn's and Colitis Foundation of America (to HNS) and National Institutes of Health grants (R37 HD12437, RO1 HD31852, PO1 DK35506 and P30-DK40561). 
12. Savidge TC, Smith MW, James PS, Aldred P. Salmonella-induced M-cell formation in germ-free mouse Peyer's patch tissue. Am J Pathol 1991;139:177-84.

13. Mottet C, Uhlig HH, Powrie F. Cutting edge: Cure of colitis by CD4+CD25+ regulatory T cells. J Immunol 2003;170:3939-43.

14. Khoo UY, Proctor IE, Macpherson AJ. CD4+ T cell down-regulation in human intestinal mucosa: Evidence for intestinal tolerance to luminal bacterial antigens. J Immunol 1997;158:3626-34.

15. Moreau MC, Gaboriau-Routhiau V. The absence of gut flora, the doses of antigen ingested and aging affect the long-term peripheral tolerance induced by ovalbumin feeding in mice. Res Immunol 1996; $147: 49-59$

16. Sudo N, Sawamura S, Tanaka K, Aiba Y, Kubo C, Koga Y. The requirement of intestinal bacterial flora for the development of an $\operatorname{IgE}$ production system fully susceptible to oral tolerance induction. J Immunol 1997;159:1739-45.

17. Wannemuehler MJ, Kiyono H, Babb JL, Michalek SM, McGhee JR. Lipopolysaccharide (LPS) regulation of the immune response: LPS converts germfree mice to sensitivity to oral tolerance induction. J Immunol 1992;129:959-65.

18. Julia V, McSorley SS, Malherbe L, et al. Priming by microbial antigens from the intestinal flora determines the ability of CD4+ T cells to rapidly secrete IL-4 in BALB/c mice infected with Leishmania major. J Immunol 2000;165:5637-45.

19. Shevach EM. Suppressor T cells: Rebirth, function and homeostasis. Curr Biol 2000;10:R572-5.

20. Suri-Payer E, Amar AZ, Thornton AM, Shevach EM. CD4+CD25+ $\mathrm{T}$ cells inhibit both the induction and effector function of autoreactive $\mathrm{T}$ cells and represent a unique lineage of immunoregulatory cells. J Immunol 1998;160:1212-8.

21. Read S, Malmstrom V, Powrie F. Cytotoxic T lymphocyte-associated antigen 4 plays an essential role in the function of CD25(+)CD4(+) regulatory cells that control intestinal inflammation. J Exp Med 2000;192:295-302.

22. Caramalho I, Lopes-Carvalho T, Ostler D, Zelenay S, Haury M, Demengeot J. Regulatory $\mathrm{T}$ cells selectively express toll-like receptors and are activated by lipopolysaccharide. J Exp Med 2003;197:403-11.

23. Cebra JJ. Influences of microbiota on intestinal immune system development. Am J Clin Nutr 1999;69:1046S-51S.

24. Falk PG, Hooper LV, Midtvedt T, Gordon JI. Creating and maintaining the gastrointestinal ecosystem: What we know and need to know from gnotobiology. Microbiol Mol Biol Rev 1998;62:1157-70.

25. Steege JC, Buurman WA, Forget PP. The neonatal development of intraepithelial and lamina propria lymphocytes in the murine small intestine. Dev Immunol 1997;5:121-8.

26. Nanthakumar NN, Dai D, Newburg DS, Walker WA. The role of indigenous microflora in the development of murine intestinal fucosyland sialyltransferases. FASEB J 2003;17:44-6.

27. Cario E, Brown D, McKee M, Lynch-Devaney K, Gerken G, Podolsky DK. Commensal-associated molecular patterns induce selective toll-like receptor-trafficking from apical membrane to cytoplasmic compartments in polarized intestinal epithelium. Am J Pathol 2002;160:165-73.

28. Cario E, Podolsky DK. Differential alteration in intestinal epithelial cell expression of toll-like receptor 3 (TLR3) and TLR4 in inflammatory bowel disease. Infect Immun 2000;68:7010-7.

29. Fusunyan RF, Nanthakumar NN, Baldeon ME, Walker WA. Evidence for an innate immune response in the immature human intestine: Toll-like receptors on fetal enterocytes. Pediatr Res 2001;49:589-93.

30. Hershberg RM, Mayer LF. Antigen processing and presentation by intestinal epithelial cells - polarity and complexity. Immunol Today 2000;21:123-8.

31. Brant SR, Picco MF, Achkar JP, et al. Defining complex contributions of NOD2/CARD15 gene mutations, age at onset, and tobacco use on Crohn's disease phenotypes. Inflamm Bowel Dis 2003;9:281-9.

32. Akira S, Takeda K, Kaisho T. Toll-like receptors: Critical proteins linking innate and acquired immunity. Nat Immunol 2001;2:675-80.

33. Medzhitov R, Preston-Hurlburt P, Janeway CA Jr. A human homologue of the Drosophila Toll protein signals activation of adaptive immunity. Nature 1997;388:394-7.

34. Mushegian A, Medzhitov R. Evolutionary perspective on innate immune recognition. J Cell Biol 2001;155:705-10.

35. Dabbagh K, Lewis DB. Toll-like receptors and T-helper-1/T-helper-2 responses. Curr Opin Infect Dis 2003;16:199-204.

36. Gewirtz AT, Navas, TA, Lyons S, Godowski PJ, Madara JL. Cutting edge:
Bacterial flagellin activates basolaterally expressed tlr5 to induce epithelial proinflammatory gene expression. J Immunol 2001;167:1882-5.

37. Melmed G, Thomas LS, Lee N, et al. Human intestinal epithelial cells are broadly unresponsive to Toll-like receptor 2-dependent bacterial ligands: Implications for host-microbial interactions in the gut. J Immunol 2003;170:1406-15.

38. Naik S, Kelly EJ, Meijer L, Pettersson S, Sanderson IR. Absence of Toll-like receptor 4 explains endotoxin hyporesponsiveness in human intestinal epithelium. J Pediatr Gastroenterol Nutr 2001;32:449-53.

39. Ortega-Cava CF, Ishihara S, Rumi MA, et al. Strategic compartmentalization of Toll-like receptor 4 in the mouse gut. J Immunol 2003;170:3977-85.

40. Rescigno M, Urbano M, Valzasina B, et al. Dendritic cells express tight junction proteins and penetrate gut epithelial monolayers to sample bacteria. Nat Immunol 2001;2:361-7.

41. Hamada H, Hiroi T, Nishiyama Y, et al. Identification of multiple isolated lymphoid follicles on the antimesenteric wall of the mouse small intestine. J Immunol 2002;168:57-64.

42. Liu YJ, Kanzler H, Soumelis V, Gilliet M. Dendritic cell lineage, plasticity and cross-regulation. Nat Immunol 2001;2:585-9.

43. Edwards AD, Diebold SS, Slack EM, et al. Toll-like receptor expression in murine DC subsets: Lack of TLR7 expression by CD8 alpha+ DC correlates with unresponsiveness to imidazoquinolines. Eur J Immunol 2003;33:827-33.

44. Liu T, Matsuguchi T, Tsuboi N, Yajima T, Yoshikai Y. Differences in expression of toll-like receptors and their reactivities in dendritic cells in BALB/c and C57BL/6 mice. Infect Immun 2002;70:6638-45.

45. Re F, Strominger JL. Toll-like receptor 2 (TLR2) and TLR4 differentially activate human dendritic cells. J Biol Chem 2001;276:37692-9.

46. Qi H, Denning TL, Soong L. Differential induction of interleukin-10 and interleukin-12 in dendritic cells by microbial toll-like receptor activators and skewing of T-cell cytokine profiles. Infect Immun 2003; 71:3337-42.

47. Higgins SC, Lavelle EC, McCann C, et al. Toll-like receptor 4-mediated innate IL-10 activates antigen-specific regulatoryT cells and confers resistance to Bordetella pertussis by inhibiting inflammatory pathology. J Immunol 2003;171:3119-27.

48. Swidsinski A, Ladhoff A, Pernthaler A, et al. Mucosal flora in inflammatory bowel disease. Gastroenterology 2003;122:44-54

49. Eggesbo M, Botten G, Stigum H, Nafstad P, Magnus P. Is delivery by cesarean section a risk factor for food allergy? J Allergy Clin Immunol 2003;112:420-6.

50. Benn CS, Thorsen P, Jensen JS, et al. Maternal vaginal microflora during pregnancy and the risk of asthma hospitalization and use of antiasthma medication in early childhood. J Allergy Clin Immunol 2002;110:72-7.

51. Bjorksten B, Sepp E, Julge K, Voor T, Mikelsaar M. Allergy development and the intestinal microflora during the first year of life. J Allergy Clin Immunol 2001;108:516-20.

52. Hooper LV, Wong MH, Thelin A, Hansson L, Falk PG, Gordon JI. Molecular analysis of commensal host-microbial relationships in the intestine. Science 2001;291:881-4.

53. Yazdanbakhsh M, Kremsner PG, van Ree R. Allergy, parasites and the hygiene hypothesis. Science 2002;296:490-4.

54. Yan F, Polk DB. Probiotic bacterium prevents cytokine-induced apoptosis in intestinal epithelial cells. J Biol Chem 2002;277:50959-65.

55. Madsen KL, Doyle JS, Jewell LD, Tavernini MM, Fedorak RN. Lactobacillus species prevents colitis in interleukin 10 gene-deficient mice. Gastroenterology 1999;116:1107-14

56. McCarthy J, O'Mahony L, O'Callaghan L, et al. Double blind, placebo controlled trial of two probiotic strains in interleukin 10 knockout mice and mechanistic link with cytokine balance. Gut 2003;52:975-80.

57. Borruel N, Carol M, Casellas F, et al. Increased mucosal tumour necrosis factor alpha production in Crohn's disease can be downregulated ex vivo by probiotic bacteria. Gut 2002;51:659-64.

58. Kalliomäki M, Salminen S, Arvilommi H, Kero P, Koskinen P, Isolauri E. Probiotics in primary prevention of atopic disease: A randomised placebo-controlled trial. Lancet 2001;357:1076-9.

59. Kalliomäki M, Salminen S, Poussa T, Arvilommi H, Isolauri E. Probiotics and prevention of atopic disease: 4-year follow-up of a randomised placebo-controlled trial. Lancet 2003;361:1869-71.

60. Lodinova-Zadnikova R, Cukrowska B, Tlaskalova-Hogenova H. Oral administration of probiotic Escherichia coli after birth reduces frequency of allergies and repeated infections later in life (after 10 and 20 years). Int Arch Allergy Immunol 2003;131:209-11. 


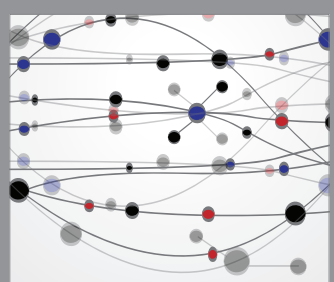

The Scientific World Journal
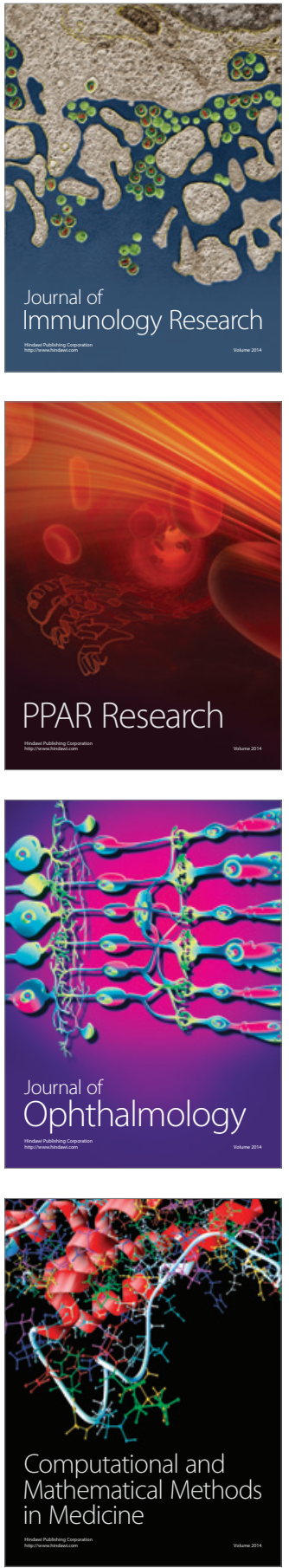

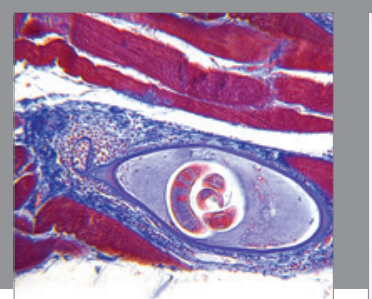

Gastroenterology Research and Practice

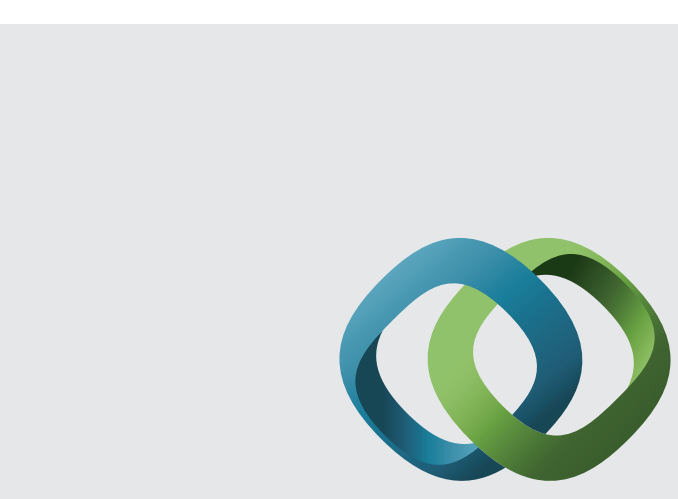

\section{Hindawi}

Submit your manuscripts at

http://www.hindawi.com
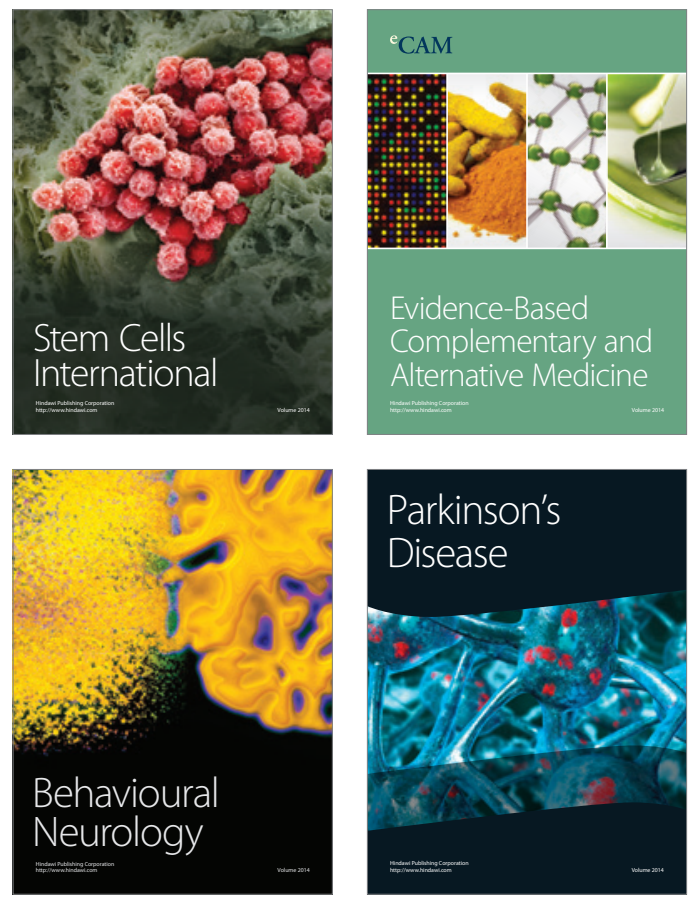
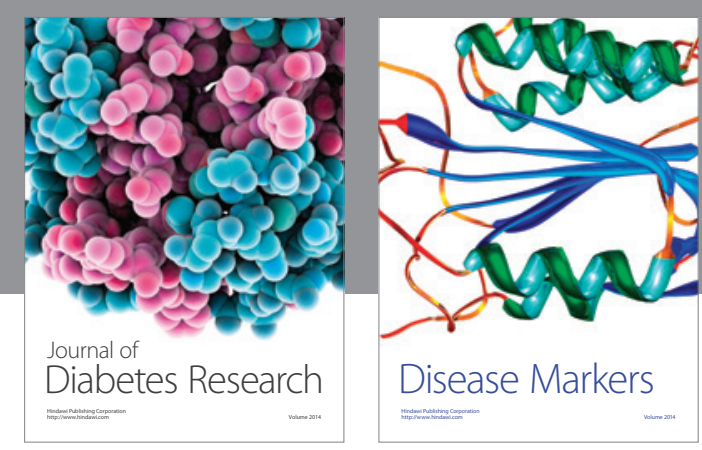

Disease Markers
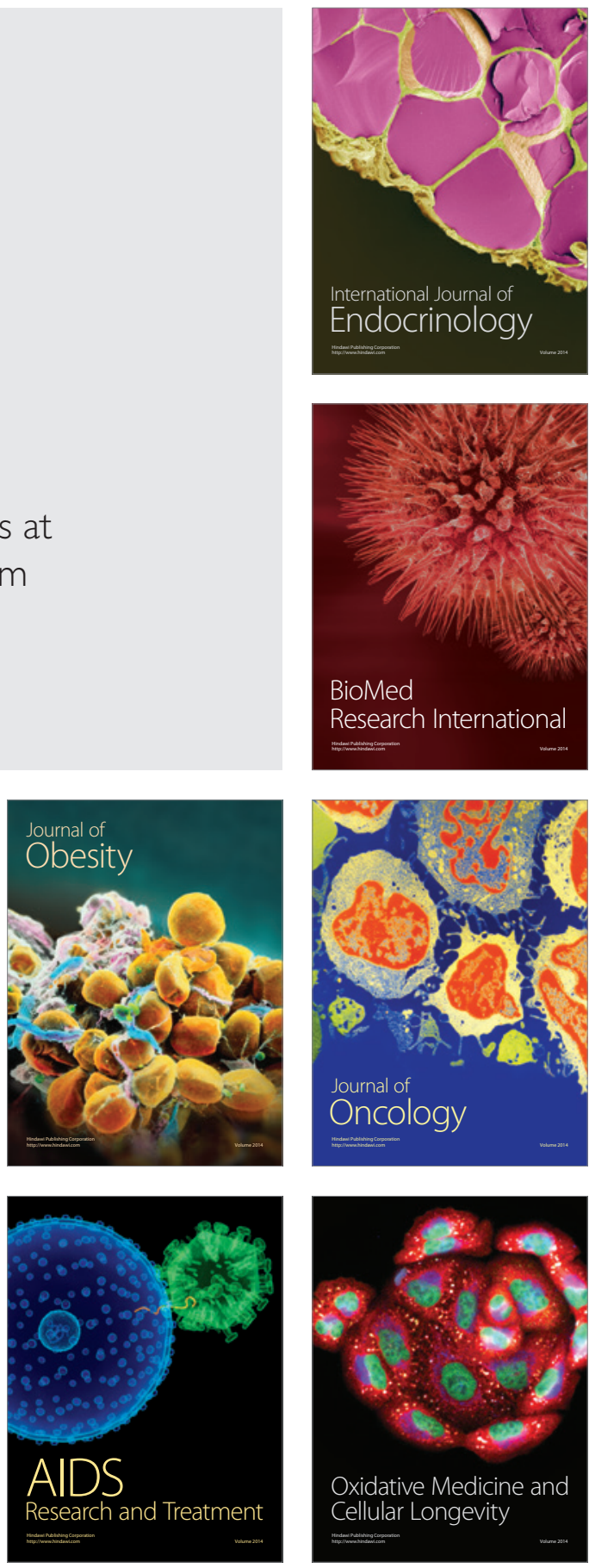